\title{
New STLV-3 strains and a divergent SIVmus strain identified in non-human primate bushmeat in Gabon
}

Florian Liégeois ${ }^{1,2^{*}}$, Vanina Boué ${ }^{2}$, Fatima Mouacha ${ }^{1}$, Christelle Butel ${ }^{1}$, Bertrand Mve Ondo ${ }^{4}$, Xavier Pourrut ${ }^{3,4}$, Eric Leroy ${ }^{3,4}$, Martine Peeters ${ }^{1}$ and François Rouet $^{2}$

\begin{abstract}
Background: Human retroviral infections such as Human Immunodeficiency Virus (HIV) or Human T-cell Lymphotropic Virus (HTLV) are the result of simian zoonotic transmissions through handling and butchering of Non-Human Primates (NHP) or by close contact with pet animals. Recent studies on retroviral infections in NHP bushmeat allowed for the identification of numerous Simian Immunodeficiency Viruses (SIV) and Simian T-cell Lymphotropic Viruses (STLV) to which humans are exposed. Nevertheless, today, data on simian retroviruses at the primate/hunter interface remain scarce. We conducted a pilot study on 63 blood and/or tissues samples derived from NHP bushmeat seized by the competent authorities in different locations across the country.

Results: SIV and STLV were detected by antibodies to HIV and HTLV antigens, and PCRs were performed on samples with an HIV or/and HTLV-like or indeterminate profile. Fourteen percent of the samples cross-reacted with HIV antigens and $44 \%$ with HTLV antigens. We reported STLV-1 infections in five of the seven species tested. STLV-3 infections, including a new STLV-3 subtype, STLV-1 and -3 co-infections, and triple SIV, STLV-1, STLV-3 infections were observed in red-capped mangabeys (C.torquatus). We confirmed SIV infections by PCR and sequence analyses in mandrills, red-capped mangabeys and showed that mustached monkeys in Gabon are infected with a new SIV strain basal to the SIVgsn/mus/mon lineage that did not fall into the previously described SIVmus lineages reported from the corresponding species in Cameroon. The same monkey (sub)species can thus be carrier of, at least, three distinct SIVs. Overall, the minimal prevalence observed for both STLV and SIV natural infections were $26.9 \%$ and $11.1 \%$ respectively.

Conclusions: Overall, these data, obtained from a restricted sampling, highlight the need for further studies on simian retroviruses in sub-Saharan Africa to better understand their evolutionary history and to document SIV strains to which humans are exposed. We also show that within one species, a high genetic diversity may exist for SIVs and STLVs and observe a high genetic diversity in the SIVgsn/mon/mus lineage, ancestor of HIV-1/SIVcpz/SIVgor.
\end{abstract}

Keywords: SIV, STLV, Non-Human primate, Zoonotic infections, Bushmeat, Gabon

\footnotetext{
* Correspondence: florian.liegeois@ird.fr

'UMI 233, «Trans VIH Ml», Recherches Translationnelles sur le VIH et les

Maladies Infectieuses Institut de Recherche pour le Développement (IRD),

University of Montpellier 1, Montpellier, France

${ }^{2}$ Laboratoire de Rétrovirologie, Centre International de Recherches Médicales

de Franceville, Franceville, Gabon

Full list of author information is available at the end of the article
} 


\section{Background}

Simian Immunodeficiency Viruses (SIV) and Simian T-cell Lymphotropic Viruses (STLV) infect a plethora of non-human primates (NHPs) in sub-Saharan Africa [1-16]. These viruses have crossed the species barrier on multiple occasions, probably by direct exposure by humans to infected blood and/or tissues when handling and butchering NHP bushmeat or from pet animals [17]. SIVcpzPtt from chimpanzees and SIVgor from gorillas in west central Africa are the precursors of Human Immunodeficiency Virus type 1 (HIV-1) group $\mathrm{M}, \mathrm{N}, \mathrm{O}$ and P [18-20], and SIVsmm from west African sooty mangabeys (Cercocebus atys) are the ancestors of the different groups (A to $\mathrm{H}$ ) of Human Immunodeficiency Virus type 2 (HIV-2) [21].

To date, five types of Primate T-cell Lymphotropic Virus (HTLV and STLV) have been identified (PTLV-1 to -5) [12], and three of them, PTLV-1 to -3 , infect both simians and humans. No simian analogue has been found to the recently discovered HTLV-4 [12], while a human counterpart has yet been reported for STLV-5, which infects an Asian monkey (Macaca arctoide). The different subtypes of HTLV-1 to -3 , originated also from apes and/or monkeys [22-25]. STLV-1 has been documented in a wide variety of old world monkey species and apes from sub-Saharan Africa and Asia, but STLV-3 has only been identified in African NHPs [12,13,26,27]. The different STLV-1 and -3 subtypes represent geographic rather than species specific clusters demonstrating a high capacity of cross-species transmissions among NHP $[12,13]$. Moreover, STLV-1 viruses are interspersed within the different HTLV-1 subtypes (A to $H$ ), and the recently discovered HTLV-3 strains are also closely related to STLV-3 strains from NHPs in the same geographic areas, indicating also numerous cross-species transmissions between NHP and humans [25,28-31].

In contrast to STLV, each NHP species is generally infected with a species-specific SIV, i.e. multiple strains from the same host species form a monophyletic clade. This was used to establish the SIV nomenclature that names the various SIVs by adding a three letters code of their common name indicating the primate species of origin (e.g., SIVcpz from chimpanzee, SIVsmm from sooty mangabey). In some cases, closely related monkey species harbour also closely related SIVs, suggesting that some of these viruses may have coevolved with their hosts for an extended period of time or that SIVs could be transmitted preferentially according to an hostswitching model, e.g., l'hoest and sun-tailed monkeys from the l'hoesti superspecies, the four species of African green monkeys (genus Chlorocebus), or SIVs from arboreal Cercopithecus species [32-34]. A single NHP species can also be infected by two different SIVs, e.g. SIVmnd- 1 and -2 in mandrills which are separated by the Ogooue River, but co-circulating SIV variants have also been observed, e.g. SIVmus- 1 and -2 in Cameroonian mustached monkeys (C. cephus cephus) [3,35]. There are also many examples of cross-species transmissions of SIVs between NHPs sharing the same habitat, e.g. SIVagm infecting African green monkeys has been transmitted to Patas monkeys in West Africa and to yellow and chacma baboons in Eastern and Southern Africa [36-38]. Cross-species transmission followed by recombination between different SIV strains can also occur, as demonstrated for SIVmus-2 infecting mustached monkeys from Cameroon, a virus resulting from the recombination of SIVgsn infecting greater spot nosed monkeys and SIVmus infecting mustached monkeys [3]. SIVcpz infecting chimpanzees is another example of cross-species transmission, followed by recombination between SIVrcm from red-capped mangabeys and SIVgsn from greater spot nosed monkeys [39]. These observations indicate that both cross-species transmission and co-infections, followed (or not) by recombination events with highly divergent lentiviral strains are possible. Overall, the evolutionary history of NHP lentiviruses has been driven by these successive events over an extended period of time.

During the last two decades, numerous studies have been conducted on wild living or captive NHPs as well as, although to a lesser extent on NHP bushmeat, broadening considerably our knowledge on simian retroviruses. Moreover, the recent identifications of the new HIV-1 group P closely related to SIVgor, the new HTLV-1 and HTLV-3 variants, and the simian foamy viruses in Cameroonian hunters with high nucleotide identity to STLV's from monkeys hunted in this region, suggest relatively recent cross-species transmissions. These findings underline the fact that zoonotic retroviral infections are still ongoing in persons exposed to NHPs $[20,25]$.

Nevertheless, our actual knowledge on the genetic diversity, their evolutionary history and the extent of human exposure to simian retroviruses remain incomplete mainly due to limited geographical and/or animal sampling. In this study, conducted in Gabon, we identified multiple retroviral infections, co-infections, and new SIV and STLV lineages in a small sample size of NHPs bushmeat, thereby confirming their wide diversity and complex evolutionary history.

\section{Results}

\section{STLV and SIV antibodies in non-human primates}

Bushmeat samples from monkeys, belonging to seven species, were obtained in villages from different areas in eight out of the nine provinces in Gabon (Figure 1); the samples encompass 28 mustached monkeys (C. cephus), 16 greater spot nosed monkeys (C. nictitans), 8 crested 


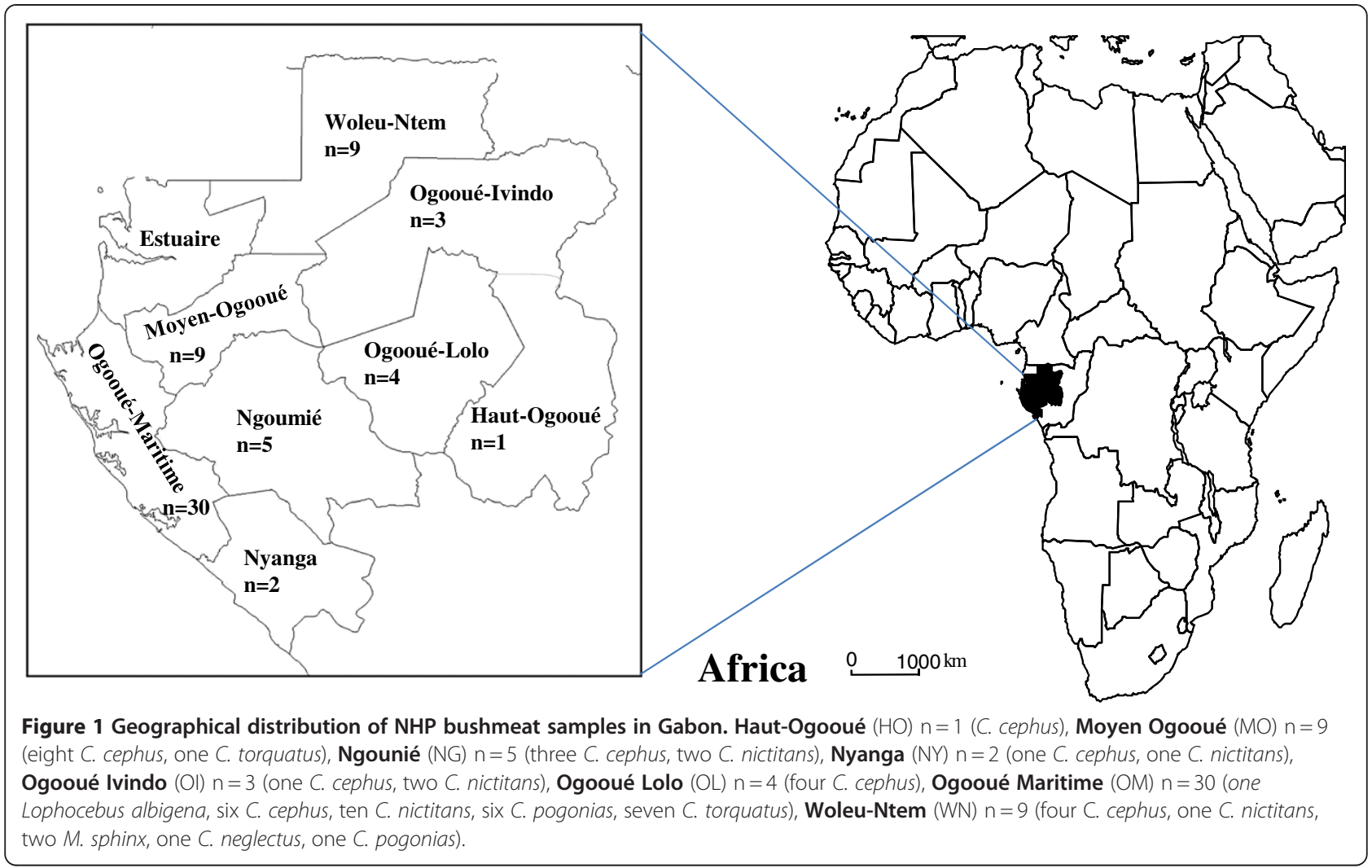

mona's (C. pogonias), 7 red-capped mangabeys (C. torquatus), 2 mandrills ( $M$. sphinx), 1 DeBrazza monkey (C. neglectus) and 1 grey-cheeked mangabey (L. albigena). Overall, 30/63 (47.6\%) samples were collected in the Ogooue Maritime province. Seven samples were collected from juvenile monkey carcasses. A total of 21 whole blood samples $(\sim 44 \%)$ tested positive or indeterminate with the HTLV-1/HTLV-2 INNOLIA assay, as summarized in Table 1. Different INNOLIA profiles were obtained ranging from HTLV-1-positive $(n=7)$, dual HTLV-1/-2-positive ( $\mathrm{n}=1)$, HTLV positive but untypable $(\mathrm{n}=4)$, to indeterminate $(\mathrm{n}=9)$. Collectively, positive HTLV cross-reactive antibodies were detected in five out of seven NHP species studied. All seven samples from juvenile monkeys were negative.

Four samples cross-reacted clearly with at least two HIV antigens in the INNOLIA HIV test (Table 2), i.e. one from C. cephus, one from M. sphinx and two from Cercocebus torquatus. Three additional samples showed either a crossreactivity with only one HIV antigen (twice C. cephus) or a very weak cross-reactivity with two HIV antigens (one $C$. nictitans). Interestingly, only the four samples presenting an HIV-like profile tested positive with their specific V3 loop peptides ELISA assay $(0.5<$ Optical Density $>1.4)$, i. e. one C. cephus, one M. sphinx and two C. torquatus (Table 2). Overall, positive HIV cross-reactive antibodies were detected in four of the seven NHP species and no juvenile monkeys were HIV sero-reactive.

\section{Molecular characterization and phylogenetic analyses of STLV Confirmation of STLV infection by confirmatory and discriminatory PCR analyses of the tax gene}

Among the 21 samples positive or indeterminate for HTLV antibodies, all seven HTLV-1-positive samples as well as the sample with an HTLV-1/-2 profile were amplified with the STLV-1 specific tax primers. Among the four untypable samples, one was amplified with the STLV-3 specific tax primers; one was reactive with both STLV-1 and STLV-3 specific tax primers; and two could not be amplified. All nine indeterminate samples were negative by generic and type specific PCRs. Among the 15 tissue samples, five were amplified with STLV-1 specific tax primers, two with STLV-3 specific tax primers; and eight were negative by generic and type specific PCRs. The minimal prevalence of STLV infection is thus 17/63 (26.9\%). All tax PCR results are summarized in Table 1.

The phylogenetic relationships of the 220-bp tax/rex sequences from the STLVs obtained in this study are shown in Figure 2. All 14 STLV-1 strains fell in the cluster of PTLV-1 strains whereas the four STLV-3 strains 
Table 1 Detection of HTLV-1 and HTLV-2 cross reactive antibodies and tax PCR results in non-human primates in Gabon

\begin{tabular}{|c|c|c|c|c|c|c|c|c|c|c|c|c|c|}
\hline \multirow{2}{*}{$\begin{array}{l}\text { Species } \\
\text { (common name) }\end{array}$} & \multirow{2}{*}{$\begin{array}{l}\text { No. of } \\
\text { animals } \\
\text { tested }\end{array}$} & \multicolumn{6}{|c|}{ Results of the InnoLIA-HTLV-1/2 confirmatory assay } & \multirow{2}{*}{$\begin{array}{l}\text { No. of } \\
\text { blood } \\
\text { samples } \\
\text { tested }\end{array}$} & \multirow{2}{*}{$\begin{array}{l}\text { No. of } \\
\text { tissue } \\
\text { samples } \\
\text { tested }\end{array}$} & \multicolumn{3}{|c|}{ No. of positive tax PCRs for } & \multirow{2}{*}{$\begin{array}{l}\text { No. of } \\
\text { negative } \\
\text { tax PCR }\end{array}$} \\
\hline & & HTLV-1 & HTLV-2 & HTLV $1+2$ & HTLV Unt & HTLV Ind & HTLV negative & & & STLV-1 & STLV-3 & STLV-1 + 3 & \\
\hline $\begin{array}{l}\text { Lophocebus albigena } \\
\text { (Grey cheeked mangabeys) }\end{array}$ & 1 & 0 & 0 & 0 & 0 & 1 & 0 & 1 & 0 & 0 & 0 & 0 & 1 \\
\hline $\begin{array}{l}\text { Cercopithecus cephus } \\
\text { (Mustached monkeys) }\end{array}$ & 25 & 3 & 0 & 0 & 1 & 5 & 16 & 9 & 3 & 3 & 0 & 0 & $9^{a}$ \\
\hline $\begin{array}{l}\text { Cercopithecus neglectus } \\
\text { (De brazza's monkeys) }\end{array}$ & 1 & 0 & 0 & 0 & 0 & 0 & 1 & 0 & & & & & \\
\hline $\begin{array}{l}\text { Cercopithecus nictitans } \\
\text { (Greater spot nosed monkeys) }\end{array}$ & 14 & 2 & 0 & 1 & 0 & 3 & 8 & 6 & 3 & 6 & 0 & 0 & $3^{b}$ \\
\hline $\begin{array}{l}\text { Cercopithecus pogonias } \\
\text { (Crested mona monkeys) }\end{array}$ & 3 & 0 & 0 & 0 & 1 & 0 & 2 & 1 & 4 & 1 & 0 & 0 & $4^{c}$ \\
\hline Mandrillus sphinx (Mandrill) & 2 & 2 & 0 & 0 & 0 & 0 & 0 & 2 & 0 & 2 & 0 & 0 & 0 \\
\hline $\begin{array}{l}\text { Cercocebus torquatus } \\
\text { (Red- capped mangabeys) }\end{array}$ & 2 & 0 & 0 & 0 & 2 & 0 & 0 & 2 & 5 & 1 & 3 & 1 & $2^{d}$ \\
\hline Total & 48 & 7 & 0 & 1 & 4 & 9 & 27 & 21 & 15 & 13 & 3 & 1 & 19 \\
\hline
\end{tabular}

${ }^{\mathrm{a}}$ Including the three tissue samples; ${ }^{\mathrm{b}}$ Including the three indeterminate blood samples; ${ }^{\mathrm{c}}$ Including three tissue samples; ${ }^{\mathrm{d}}$ Including two tissue samples. 
Table 2 Detection of HIV-1 and HIV-2 cross reactive antibodies and partial pol PCR results in non-human primates in Gabon

\begin{tabular}{|c|c|c|c|c|c|c|c|c|c|c|}
\hline \multirow{2}{*}{$\begin{array}{l}\text { Species } \\
\text { (Common name) }\end{array}$} & \multirow{2}{*}{$\begin{array}{l}\text { No. of } \\
\text { animals } \\
\text { tested }\end{array}$} & \multicolumn{3}{|c|}{ Results of the InnoLIA-HIV-1/2 confirmatory assay } & \multirow{2}{*}{$\frac{\text { Peptides results }}{\text { pos }}$} & \multirow{2}{*}{$\frac{\text { V3 ELISA }}{\text { neg }}$} & \multirow{2}{*}{$\begin{array}{l}\text { No. of } \\
\text { blood } \\
\text { samples } \\
\text { tested }\end{array}$} & \multirow{2}{*}{$\begin{array}{l}\text { No. of } \\
\text { tissue } \\
\text { samples } \\
\text { tested }\end{array}$} & \multirow{2}{*}{$\begin{array}{l}\text { No. of } \\
\text { samples } \\
\text { positive } \\
\text { for partial } \\
\text { pol } \\
\text { sequences }\end{array}$} & \multirow{2}{*}{$\begin{array}{l}\text { No. of } \\
\text { samples } \\
\text { negative } \\
\text { for pol } \\
\text { sequences }\end{array}$} \\
\hline & & HIV like $^{a}$ & HIV Ind ${ }^{b}$ & HIV negative & & & & & & \\
\hline $\begin{array}{l}\text { Lophocebus albigena } \\
\text { (Grey cheeked mangabeys) }\end{array}$ & 1 & 0 & 0 & 1 & 0 & 1 & 0 & & & \\
\hline $\begin{array}{l}\text { Cercopithecus cephus } \\
\text { (Mustached monkeys) }\end{array}$ & 25 & 1 & 2 & 22 & 1 & 24 & 3 & 3 & 1 & $5^{c}$ \\
\hline $\begin{array}{l}\text { Cercopithecus neglectus } \\
\text { (De brazza's monkeys) }\end{array}$ & 1 & 0 & 0 & 1 & 0 & 1 & 0 & & & \\
\hline $\begin{array}{l}\text { Cercopithecus nictitans } \\
\text { (Greater spot nosed monkeys) }\end{array}$ & 14 & 0 & 1 & 13 & 0 & 14 & 1 & 3 & 0 & 4 \\
\hline $\begin{array}{l}\text { Cercopithecus pogonias } \\
\text { (Crested mona monkeys) } \\
\end{array}$ & 3 & 0 & 0 & 3 & 0 & 3 & 0 & 4 & 0 & 4 \\
\hline $\begin{array}{l}\text { Mandrillus sphinx } \\
\text { (Mandrills) }\end{array}$ & 2 & 1 & 0 & 1 & 1 & 1 & 1 & 0 & 1 & 0 \\
\hline $\begin{array}{l}\text { Cercocebus torquatus } \\
\text { (Red-capped mangabeys) }\end{array}$ & 2 & 2 & 0 & 0 & 2 & 0 & 2 & 5 & 5 & $2^{d}$ \\
\hline Total & 48 & 4 & 3 & 41 & 4 & 44 & 7 & 15 & 7 & 15 \\
\hline
\end{tabular}

aplasma samples were scored as HIV-like when they reacted with at least two HIV antigens and had a band intensity equal to or greater than the assay cutoff (+/-) lane; ${ }^{\mathrm{b}}$ Samples that reacted less strongly but still

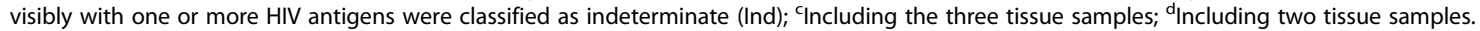


clustered with PTLV-3 sequences. Interestingly, STLV-3 strains have only been identified in red-capped mangabeys (C. torquatus) with one strain, which seemed to be more divergent than other new STLV-3 strains.

The phylogenetic relationships of these new viruses within either STLV-1 or STLV-3 lineages were further analyzed based on LTR (STLV-1) and tax-pX-LTR (STLV-3) sequence comparison as described below.

\section{Analysis of STLV-1 LTR sequences}

A 450-bp fragment of the LTR region was sequenced in 10 out of the 14 STLV-1-infected animals: one $M$. sphinx, four C. cephus, two C. torquatus and three $C$. nictitans. We failed to amplify the LTR region for four animals (one M. sphinx, one C. pogonias and two $C$. nictitans).

As for the phylogeny of the tax-rex region, nine out of the ten new STLV-1 LTR sequences clustered with the African PTLV-1 strains and more precisely with HTLV-1 subtype D (Figure 3 ). Among the HTLV-1 subtype D clade, the new STLV-1 strains from $C$. torquatus, $C$. cephus and C. nictitans were closely related to each other and to previously described STLV-1 sequences from Cercopithecus monkeys from Cameroon [12,41,42]. The new STLV-1 strain from $M$. sphinx is close to the reported STLV-1 strains from mandrills in Cameroon and Gabon [12,41-43]. Interestingly, one STLV-1 strain from C. cephus (CceWN411GAB) was clustered with the

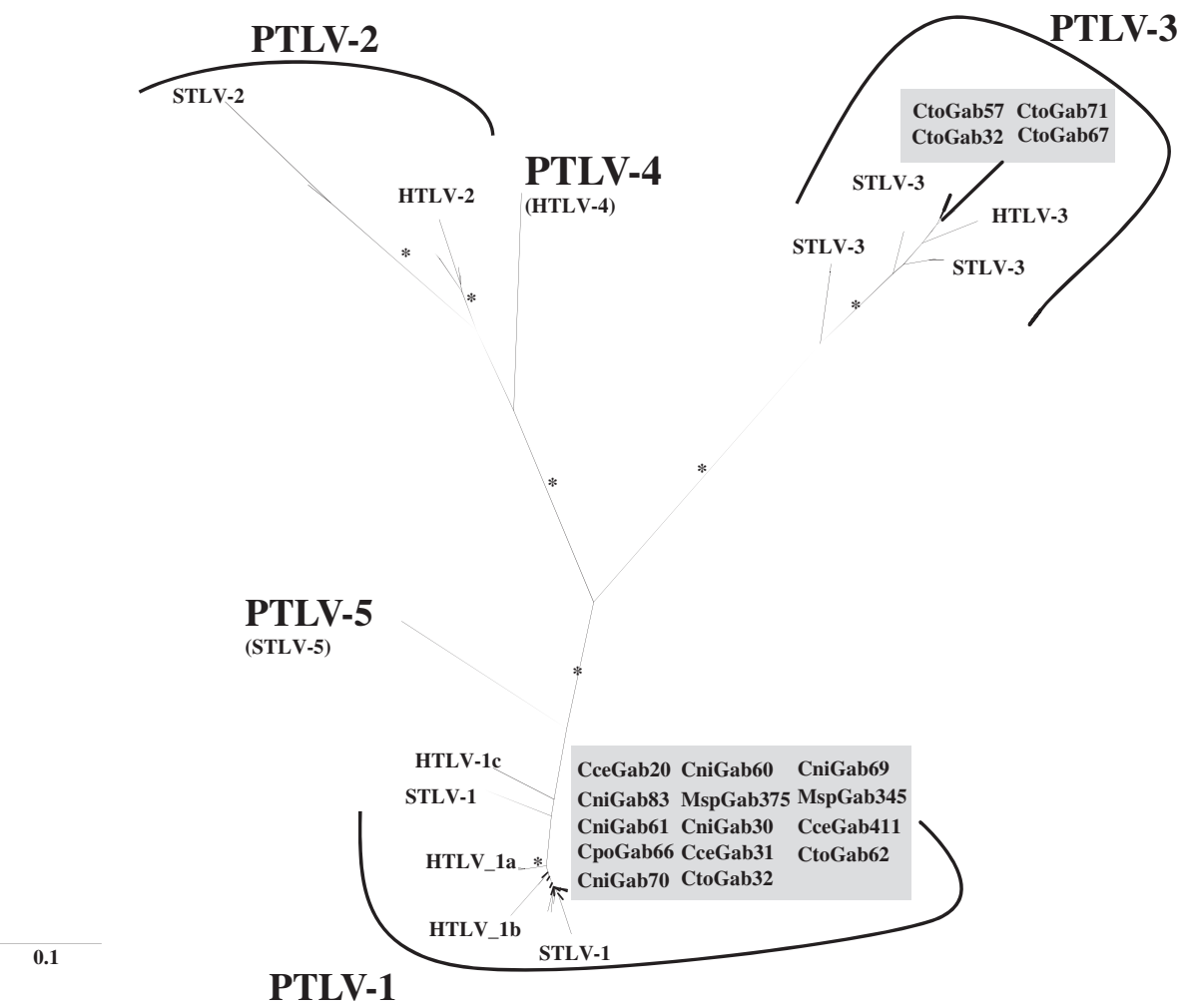

Figure 2 Phylogenetic analysis of STLV tax-rex sequences. PTLV phylogeny inferred using 220-bp tax-rex sequences. Reference sequences used were as follow: HTLV-1 (RKI3Ger_AF042071, TSP-1_M86840, HS35_AF033817, BOI_L36905, MT2_L03561, ATK-1_j02029, ATL-YS_U19949, WHP_AF259264, EL_M67514, MEL5_L02534), STLV-1 (Cce01CM1374_ AM746629, Cce01CM3020_AM746632, Cpo01CM2324_AM746633, Cpo01CM2230_AM746634, Cni01CM4078_AM746635, Cce01CM2141_AM746636, Cce01CM1445_AM746638, Cce01CM2205_AM746639, Cni01CM2198_AM746640, Mta 00cm265_AY496616, Tan90_AF074966, Cta01CMS75_AY496618, Cpo99cm190_AY496615, Cpo01cm1228_AY496612, Mnd 98cmB111_AY496617, Cni01cm1040_AY496608, Cag01 cm1312_AY496614, Cag 01cm1135_AY496610, TE4_Z46900), HTLV-II (GAB_Y13051, GU_X89270, NRA-P_L20734, G12_I11456, Efe2_Y14365, G2_AF074965, RP329_AF326583, SP-WV_AF139382, k96_AF326584, Mo_M10060), STLV-2 (PanP_U90557, PP1664_NC001815), HTLV-3 (Pyl 43_DQ020492), STLV-3 (Lal01CM2008_ AM746647, Lal01CM4009_ AM746650, Cag02CM4101, PPA-F3_AF5177775, PH969_Y07616, TGE-2117_AY217650, hyb2210_AF378162,CTO-604_NC003323, Pha7550_AF378160, Cag01cm1184_AY496593, Cni227_AF412120,Cni217_ AY039033), HTLV-4 (1863LE_NC_011800), STLV-5 (MarB43_AY590142). Numbers correspond to internal branch support derived from 1000 bootstrap replicates (only values above $\geq 80 \%$ are shown and represented by an asterisk). Scale bar represents the number of nucleotide substitutions per site. Groves' primate taxonomy nomenclature is used [40]. Non-human primates are coded using the first letter of the genus followed by the first two letters of the species name: $\mathrm{Cni}=$ Cercopithecus nictitans, Cce =Cercopithecus cephus, Msp = Mandrillus sphinx, Cto = Cercocebus torquatus, $\mathrm{Cpo}=$ Cercopithecus pogonias. Sequences in bold text and in grey rectangles are from the current study. 


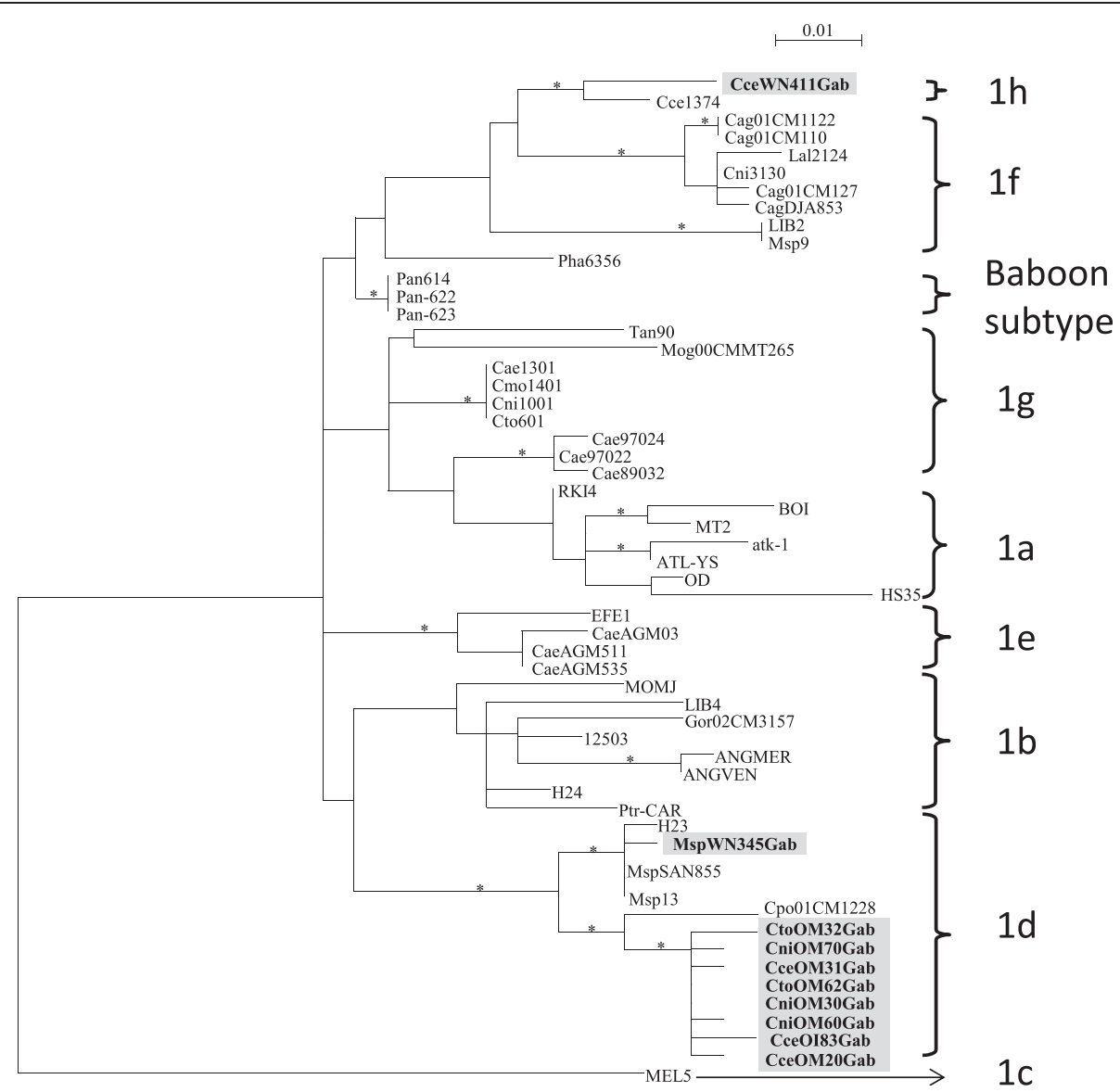

Figure 3 Phylogenetic analysis of STLV-1 LTR sequences. Inference of PTLV-1 phylogeny using 450-bp LTR sequences. Reference sequences used were as follow: PTLV-1a (BOI_L36905, MT2_Z31660, atk-1_J02029, ATL-YS_U19949, OD_U12805, OD_U12805, RKI4_AF054627), PTLV-1b (MOMJ_Z31659, LIB4_Y17019, Gor02CM3157_AY496635, 12503_L76309, ANGMER_AY026858, ANGVEN_AY026857, H24_L76308, PTR-

CAR_AF384871), PTLV-1c (MEL5_L02534), PTLV-1d (H23_L76312, MSPSAN855_AF384870, MSP13_AF045933, Cpo01CM1228_AY496628), PTLV-1e (EFE1_Y17014, CAEAGM03_AY026848, CAEAGM511_AY026847, CAEAGM535_AY026846), PTLV-1f (Cag01CM1122_AY496630,

Cag01CM1106_AY496629, Cag01CM1272_AY496633, CAGDJA853_AF384872, LIB2_Y17017, Msp9_AF045932,Lal01CM2124_AM712678,

Cni01CM3130_AM712679, PTLV-1g (Tan90_AF074966, Mog00CMMT265_AY496636, CAE1301_AY026852, CMO1401_AY026853, Cni1001_AY026854, Cto601_AY026855, Cae97024_AY026849, Cae97022_AY026850, Cae89032_AY026851), PTLV-1h (Cce01CM1374_AM712677), Baboon subtype (Pha6356_Y13347, Pan614_AY026844, Pan622_AY026843, Pan623_AY026842). Numbers correspond to internal branch support derived from 1000 bootstrap replicates (only values $\geq 80 \%$ are shown and represented by an asterisk). Scale bar represents the number of nucleotide substitution per site. Groves' primate taxonomy nomenclature is used [40]. Non-human primates are coded using the first letter of the genus followed by the first two letters of the species name: $\mathrm{Cni}=$ Cercopithecus nictitans, $\mathrm{Cce}=$ Cercopithecus cephus, Msp = Mandrillus sphinx, Cto =Cercocebus torquatus, $\mathrm{Cae}=$ Chlorocebus aethiops, Gor = Gorilla gorilla, Pha = Papio hamadryas, Pan = Papio Anubis, Mog = Miopithecus ogoouensis, Ptr = Pan troglodytes . Sequences in bold text and in grey rectangles are from the current study.

C. cephus (Ccep1374) STLV-1 strain from a new subtype $\mathrm{H}$ characterized in Cameroon [12].

\section{Phylogenetic analysis of STLV-3 tax-pX-LTR sequences}

The 900-bp fragment spanning the tax-rex and pX-LTR region was sequenced from three of the four STLV-3 infected red-capped mangabeys (Figure 4). We failed to amplify STLV-3 tax-pX-LTR sequence from one C. torquatus sample. Two new STLV-3 sequences (CtoOMGab32, CtoOMGab67) clustered within the PTLV-3 subtype B and formed a specific sub-clade together with the STLV-3 strains from wild caught Cameroonian $C$. torquatus and $C$. agilis monkeys and with the HTLV-3 Pyl 43 and Loback 18 strains from humans (Figure 4) [12,41,44-46]. Interestingly, one new STLV-3 strain (CtoOMGab57) did not cluster with the previously identified PTLV-3 strains and did not group at a significant bootstrap level within any of the actual described STLV3 subtypes, strongly suggesting the identification of a new lineage (Figure 4). 


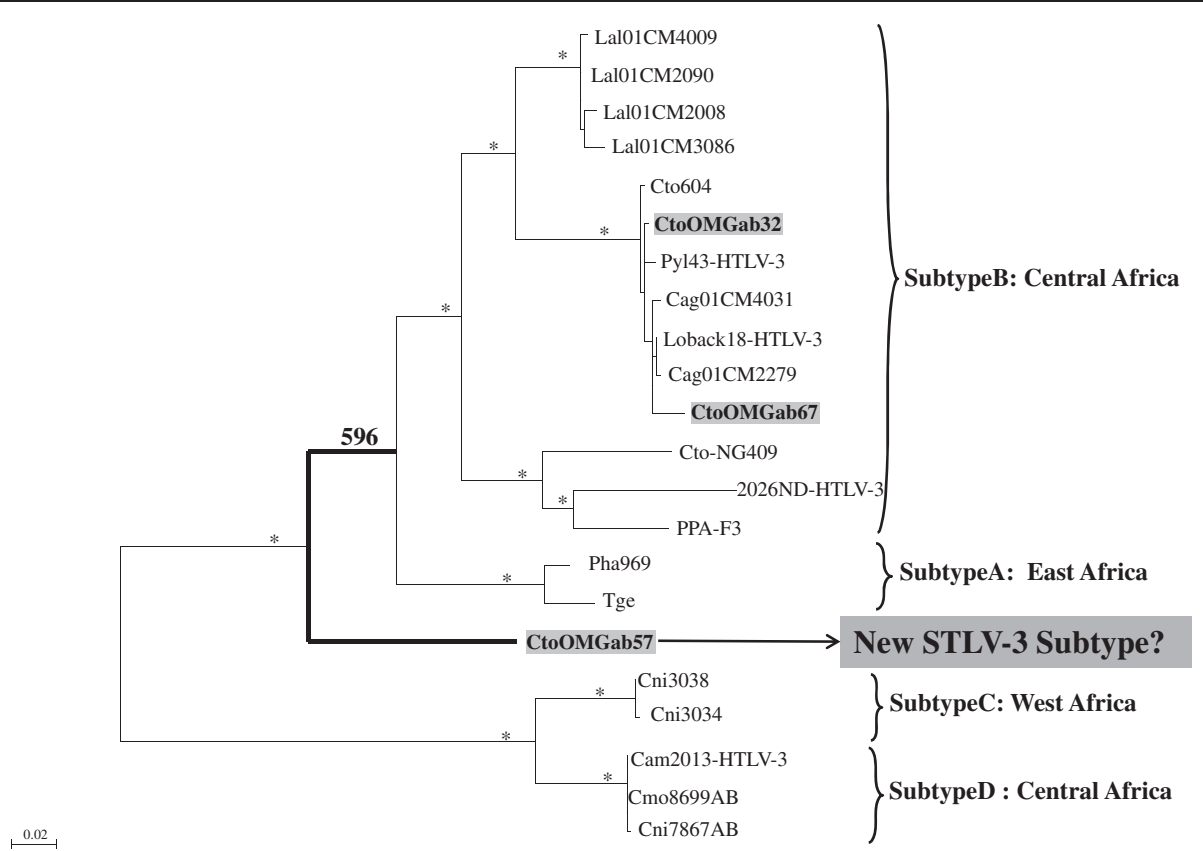

Figure 4 Phylogenetic analysis of STLV-3 $p X$-LTR sequences. Inference of PTLV-3 phylogeny using 900-bp tax-pX-LTR sequences. Reference sequences used were as follow: STLV-3 (Cto604_AF391797, Cto-NG409_AY222339, Ppa-F3_AF517775, TGE-2117_AY217650, Pha969_Y07616, Lal01CM2090_AM712666, Lal01CM3086_AM712667, Lal01CM4009_AM712672, Lal01CM2008_AM712673, Cag01CM4031_AM712670, Cag01CM2279_AM712669, Cmo8699AB_EU231644, Cni7867AB_EU152281, Cni3034_FJ957877, Cni3038_FJ957878), HTLV-3 (Pyl 43_DQ462191, Loback 18_EU649782, 2026ND_DQ093792, Cam2013_GQ463602). Numbers correspond to internal branch support derived from 1000 bootstrap replications (only values $\geq 80 \%$ are shown and represented by an asterisk except for the non-significant bootstrap percentage (59.6\%) for the putative new STLV-3 subtype CtoOMGAB57). Scale bar represents the number of nucleotide substitution per site. Groves' primate taxonomy nomenclature is used [40]. Non-human primates are coded using the first letter of the genus followed by the first two letters of the species name: $\mathrm{Cto}=$ Cercocebus torquatus, $\mathrm{Cag}=$ Cercocebus agilis, Lal = Lophocebus albigena, Cni=Cercopithecus. Nictitans, Ppa = Papio hamadryas papio, Tge $=$ Therppithecus gelada, Pha = Papio hamadryas. Sequences in bold text and in grey rectangles are from the current study.

\section{Molecular characterization and phylogenetic analyses of SIV \\ Confirmation of SIV infection by PCR analyses of the partial pol gene}

SIV infections were confirmed in four of the seven SIV seroreactive samples and in three of the 15 monkey tissue samples, including five C. torquatus, one C. cephus and one M. sphinx. Only the four samples presenting an HIV-like profile and tested positive with their specific V3 loop peptides ELISA were SIV PCR positive, which is consistent with a better specificity and sensitivity of the in-house EIA specific test compared to SIV antibodies/HIV antigens cross reactivity tests as previously reported [2].

The phylogenetic tree analysis revealed the presence of a new SIV variant in mustached monkey (C. cephus) (Figure 5) whereas the new SIV sequences from M. sphinx and $C$. torquatus fell within their respective lineages. All new SIVrcm strains from Gabon formed a specific subclade with the previously described SIVrcmGab1 from a captive red-capped mangabey from Gabon and interestingly with SIVagi from Cercocebus agilis identified in Cameroon. However, the phylogenetic topology was not supported by a significant bootstrap value probably caused by the small fragment size analyzed.

\section{Phylogenetic analyses of partial SIVrcm gag, pol and env sequences}

As depicted in Figure 6, for the 470 bp gag fragment, SIVrcm-10GabOM32, 62, 67 and 71 formed a sub-clade and are closest to SIVrcm from Cameroon and Nigeria and SIVagi, whereas SIVrcm-10GabOM57 was more closely related to SIVrcmGab1 from Gabon. In the 1800 bp pol fragment, all SIVrcm strains from Gabon clustered together (although SIVrcm-10GabOM57 and SIVrcmGab1 occupied a basal position in the tree topology) whereas SIVrcm/agi strains from Cameroon and Nigeria formed a separate sub-clade. In the $500 \mathrm{bp}$ env fragment, all SIVrcm strains from Gabon, Cameroon and Nigeria as well as SIVagi clustered together but no 


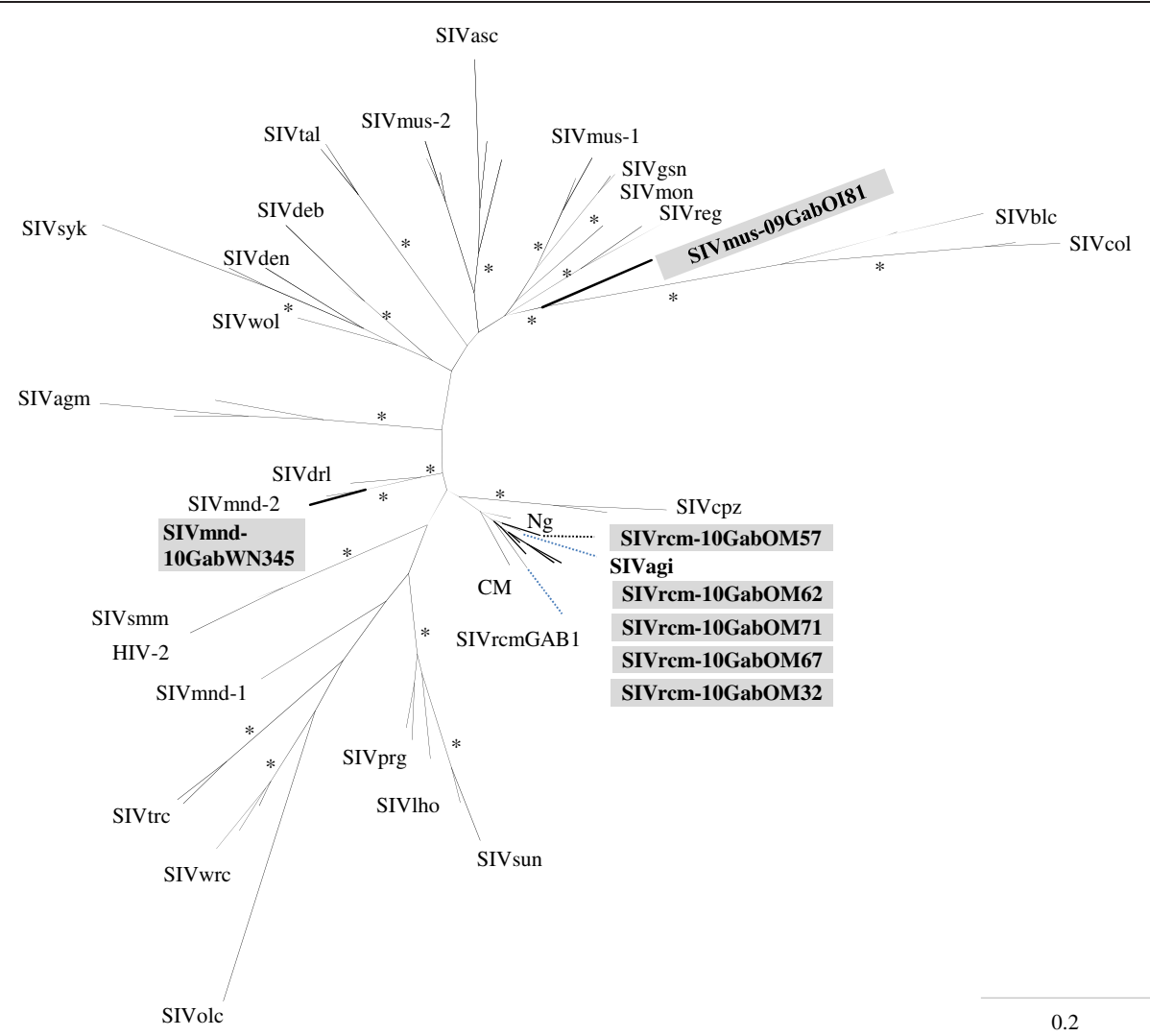

Figure 5 Phylogenetic analysis of partial SIV pol sequences. Phylogenetic relationships of the newly derived SIVs in partial pol sequences to representatives of the other SIV lineages. Reference sequences used were as follow: SIVwrcPbt (western red colobus monkey, Piliocolobus badius temminckii) 05GMX02_AM937062, SIVwrcPbb (western red colobus monkey, Piliocolobus badius badius) 98CI04_AM713177,

SIVwrcPbb97Cl14_AM745105, SIVtal (talapoin monkey, Miopithecus ogoouensis) 00CM266_AY655744, SIVtal01CM8023_AM182197, SIVmon (mona monkey, Cercopithecus mona) 99CMCML1_AY340701, SIVgsn (greater spot nosed monkey, Cercopithecus nictitans) 99CM166_AF468659, SIVgsn99CM71_AF468658, SIVsyk (Sykes monkey, Cercopithecus albogularis) KE51_AY523867, SIVsyk173_L06042, SIVmus-1 (Mustached monkey, Cercopithecus cephus) 01CM1085_AY340700, SIVmus- 1.01CMCM1239_EF070330, SIVmus-2 01CM1246_EF070329, SIVdeb (DeBrazza monkey, Cercopithecus neglectus) 99CMCM40_AY523865, SIVdeb99CMCM5_AY523866, SIVden (Dents monkey, Cercopithecus denti) CD1_AJ580407, SIVsun (Suntailed monkey, Cercopithecus solatus) L14_AF131870, SIVIho (L'Hoest monkey, Cercopithecus I'hoesti) 7_AF075269, SIVmnd-1 (Mandrill, Mandrillus sphinx) Gab1_M27470, SIVmnd-2 M14_AF328295, SIVdrl (Drill, Mandrilus leucophaeus) FAO_AY159321, SIVolc (olive colobus monkey, Procolobus verus) 97CI12_FM165200, SIVcol (black and white colobus monkey, Colobus guereza) CGU1_AF301156, SIVagmver (Afican green monkey, Chlorocebus vervet)155_M29975, SIVagmgri (Afican green monkey, Chlorocebus grivet) 677_M66437, SIVagmTAN (Afican green monkey, Chlorocebus tantalus) 1_U58991, SIVrcm (red-capped mangabey, Cercocebus torquatus) GAB1_AF382829, SIVrcmNG411_AF349680, SIVrcm-02CM8081_ HM803689, SIVagi (Agile mangabey, Cercocebus agilis) 00CM312_ HM803690, SIVcpzPts (Chimpanzee, Pan troglodytes schweinfurtii) TAN1_AF447763, SIVcpzPtt_(Chimpanzee, Pan troglodytes troglodytes) AF103818, SIVsmm (Sooty mangabey, Cercocebus atys) US-H9_M80194, HIV-2Rod_M15390, SIVreg (Red eared guenon, Cercopithecus erythrotis) REG016_HM363408, SIVreg-REG001_ HM363406, SIVblc (Black colobus monkey, Colobus satanas) BCM91_ HM363421, SIVbcm-BCM307__HM363423, SIVprg (preussis monkey, Cercopithecus preussi insularis) PRG138_ HM363425, SIVprgPRG056_ HM363424, SIVwol (Wolf's monkeys, Cercopithecus mona wolfi) 09DRC5_JN020273, SIVtrc (Tshuapa red colobus (Piliocolobus tholloni) 09DRC67_JN020274, SIVtrc-09DRC73_JN020275, SIVasc (redtailed monkey, Cercopithecus ascanius) 09DRC93_JN020276, SIVasc-09DRC99_JN020277, SIVasc-10DRC110_JN020278, SIVasc-10DRC149_JN020279. The newly identified SIV strains in this study are highlighted in grey rectangles and in bold text.. Within the SIVrcm clade, acronyms CM, Ng and Gab corresponded to the geographical origin of these SIVrcm strains (CM=Cameroon, $\mathrm{Ng}=$ Nigeria and $\mathrm{Gab}=\mathrm{Gabon})$. The unrooted trees were inferred from 300 bp nucleotides. The analyses were performed using discrete gamma distribution and GTR model. The starting tree was obtained by using phyML. One thousand bootstrap replications were performed to assess confidence in topology (only values $\geq 80 \%$ are shown and represented by an asterisk). Scale bar represents the number of nucleotide substitution per site.

sub-clade appeared clearly. More detailed analysis of the sequenced pol fragment did not reveal inter SIVrcm recombinants or with other SIV lineages.
Phylogenetic analyses of partial SIVmus env sequences

To further document the existence of a putative new SIVmus variant in mustached monkeys from Gabon, we 


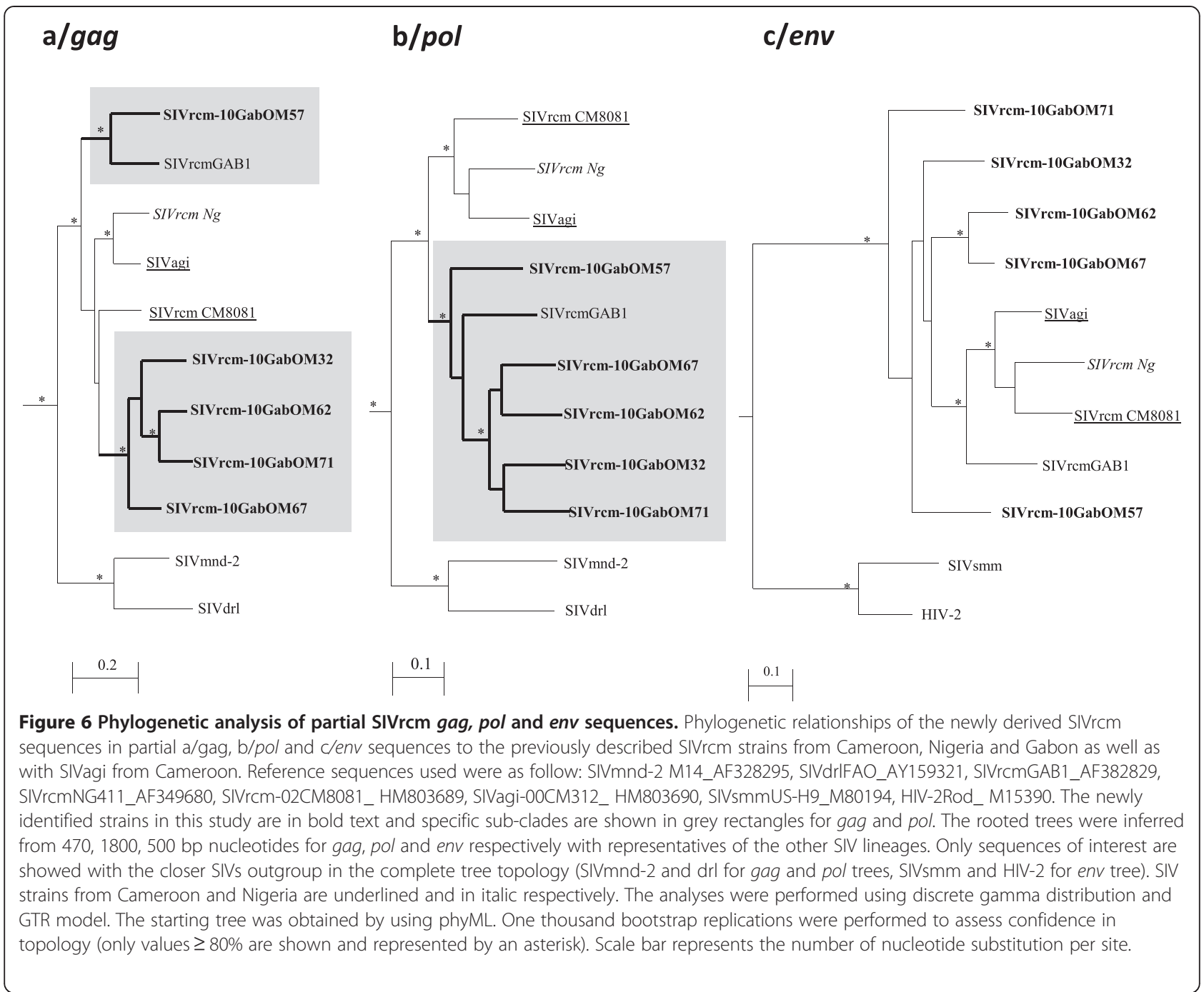

compared a 1900 bp SIVmus-09GabOI81 partial env sequence with env sequences from all other SIV lineages available in GenBank. SIVmus-09GabOI81 partial env sequence was significantly closer to SIVmon/gsn/mus lineage than to the other SIV lineages (Figure 7a). All SIV strains composing the SIVmon/gsn/mus lineages, including the new SIVmus-09GabOI81 were equidistant to each other with nucleotide sequence identities varying from 68 to $73 \%$ (data not shown). These data were confirmed by the Simplot analysis (and by bootscan analysis as well, data not shown), which also showed that the new strain was not a recombinant virus with any of the other know SIVgsn/mus/mon strains or another SIV lineage (Figure 7b). Although SIVmus-09GabOI81 fell within the SIVmon/gsn/mus lineage from Cameroonian arboreal Cercopithecus monkeys, in both pol and env tree topologies, this lentivirus occupied a basal position within this lentiviral lineage. Overall, these results suggested that mustached monkeys in Gabon are infected with a SIVmus lineage that is different from SIVmus-1 and 2 identified in Cameroonian monkeys [3].

\section{SIV and STLV co-infections}

In this study, co-infections with SIV and STLV were only observed in red-capped mangabeys, with four (on a total of seven) animals dually infected with SIV and STLV-1 or -3 (CtoOMGab57, 62, 67 and 71) and one triply infected with SIV, STLV-1 and STLV-3 (CtoOMGab32).

\section{Discussion}

Simian retroviruses may easily jump the species barrier leading to human retroviral infections such as HIV/ AIDS, thereby causing considerable damages for human health. Numerous studies have documented retroviruses 


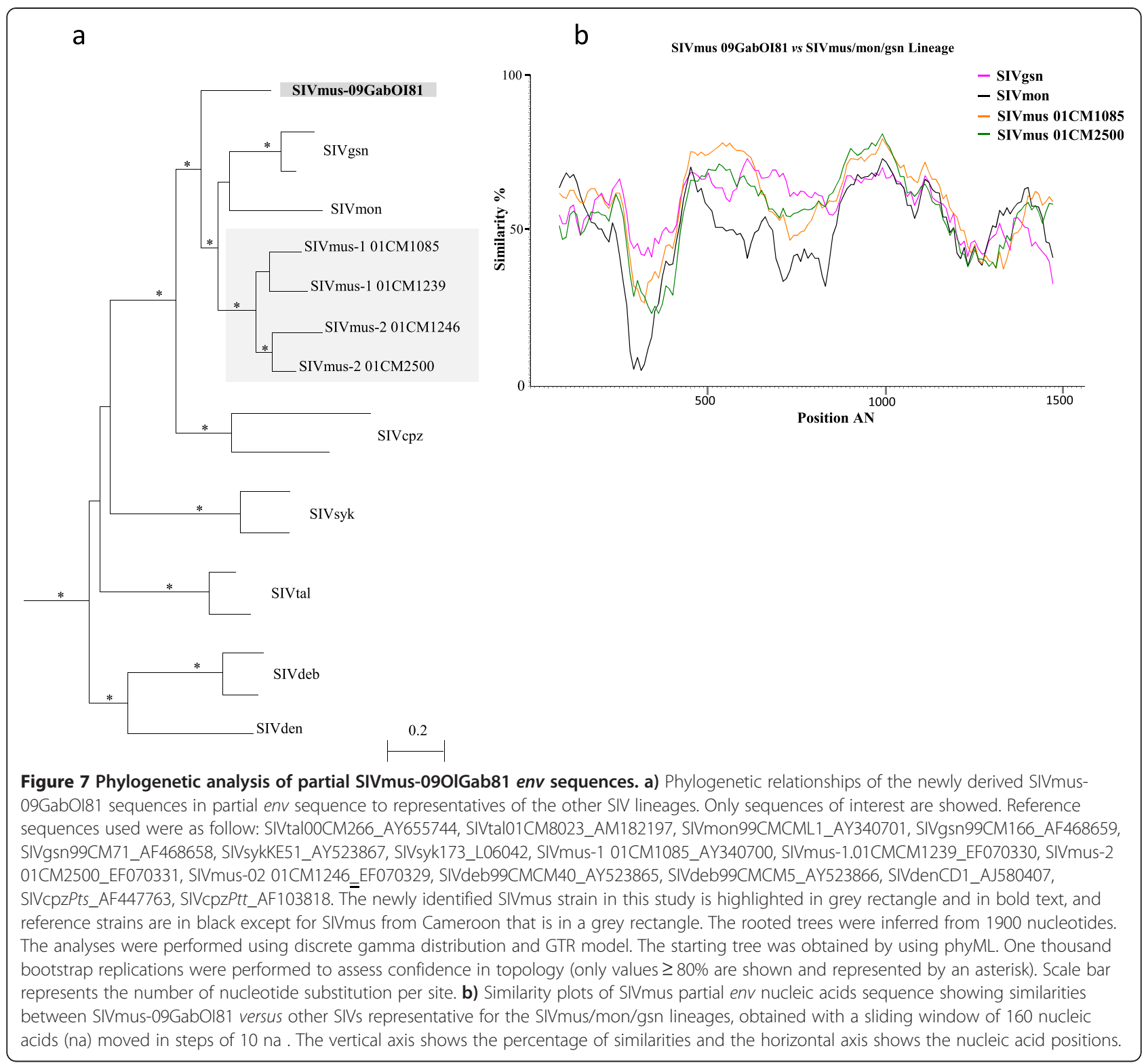

in NHP species but most of them have been conducted in captive, breeding colonies, and to a lesser extent on wild living monkeys. Although these reports contribute to our knowledge on genetic diversity of retroviruses and evolution in their natural hosts, they do not provide data on their prevalence and the extent of human exposure to these viruses $[4,6,10,11,15,16,27,32,35-37,42,43,47]$. Indeed, the most probable ways of zoonotic retroviral infections are related to hunting and butchering of NHPs or by injuries like bites or scratches caused by pet primates. Studies on retroviruses in NHP bushmeat are limited and have been only conducted in few sampling sites in Sierra Leone, Cameroon, Bioko Island, and the Democratic Republic of Congo (DRC) [2,5,12-14,25,41,
48-51]. These studies showed heterogeneous exposure according to geographic areas, both in terms of the prevalence and the genetic diversity of circulating strains.

Here, we report a pilot study on NHP bushmeat in Gabon. At least 19 NHP species inhabit Gabon, including Cercopithecinae, Colobinae and apes [52]. Despite our small sample size (63 samples from seven different species), our work revealed the presence of new STLV-1 $(\mathrm{n}=10)$ and STLV-3 $(\mathrm{n}=3)$ strains, with STLV-1 infections in C. cephus, C. nictitans, Mandrillus sphinx and C. torquatus, and STLV-1+-3 dual infections in C. torquatus. In addition, one $C$. torquatus was SIV/STLV-1/STLV-3 coinfected (triple retroviral infection). Finally, we were able to partially characterize a new SIV strain in one C. cephus. 
Nine of the ten Gabonese STLV-1 strains fell consistently in the west Central Africa STLV-1 subtype D lineage. One strain (Cce WNGab411) from C. cephus clustered within the putative STLV-1 subtype $\mathrm{H}$ clade which was recently described in south Cameroon from the same species (Cce 01CM1374) [12]. The close relationship between these two STLV-1 strains may be explained by the small geographical distance separating them, which does not exceed $150 \mathrm{~km}$. It also suggests that STLV-1 subtype $\mathrm{H}$ strains may be widely circulated among $C$. cephus and possibly also in other NHP species in Central Africa.

In our survey, STLV-3 strains were only detected in $C$. torquatus sampled in the Ogooue Maritime province, which is the geographic range where this species can be encountered, i.e. coastal areas from southeast Nigeria to Gabon. Two of them clustered strongly together with STLV-3 strains from C. torquatus and C.agilis identified in Cameroon and with the human Pyl 43 and Loback 18 HTLV-3 strains also isolated in Cameroon [12,41,44-46]. To date, HTLV-3 infections have only been reported in Cameroon. The identification of STLV-3 infected hunted NHPs in our study suggests that HTLV-3 strains could also be present in Gabon. In addition, we found a new STLV-3 strain that did not cluster within PTLV-3 subtypes known so far. This strain could represent a new STLV-3 subtype. Overall, our results indicate that at least two different STLV-3 lineages or subtypes (Cto OMGab67 and 32 vs Cto OMGab57) co-circulate within the same monkey species from the same geographical area.

All SIVrcm from Gabonese C. torquatus fell in the SIVrcm lineage and potential sub-clades in gag and pol genes were observed. Although we did not observe recombination events in the pol gene, we could not exclude that SIVrcm recombinant forms circulate within close red-capped mangabey groups such as reported within western red colobus in the Ivory Coast's Tai forest [53]. Nonetheless, further investigations and analyses within different wild living red-capped mangabey groups will allow the epidemiological dynamic of this SIV to be determined. Besides, red-capped mangabeys are likely infected with a monophyletic SIV lineage independently of the natural barriers separating their habitat along the coast of the Guinean gulf. These data suggest a long-standing lentiviral infection among these animals. Interestingly, five out of the seven samples tested $(\sim 70 \%)$ from red-capped mangabeys were co-infected with both STLV and SIV raising the number of monkey species known to harbor retroviral coinfections, such as previously documented in a few other monkey species $[5,7,9,13]$. Of note, retroviral coinfections are probably underestimated since surveys characterizing the different existing simian retrovirus
(SIV, STLV and Simian Foamy Viruses) from a same population are very scarce.

Finally, we described a new SIV strain infecting the $C$. cephus cephus subspecies (mustached monkeys) sampled north of the Ogooue River in Gabon. The cephus superspecies is composed of six species and 14 subspecies. In West Central Africa, one species (C. cephus) consisting of four subspecies are present: C. c. erythrotys in Cameroon above the Sanaga River and in Bioko Island, $C$. $c$. cephode south of the Ogooue River in Gabon, C. c. ngottoensis between the Sangha and the Congo-Oubangui Rivers in Congo and C. c. cephus inhabiting the largest part of west Central Africa from the south of the Sanaga River to the north of the Ogooue River and following the right bank of the Congo River [54].

As reported by Aghokeng et al. in Cameroon, two distinct lentiviruses, SIVmus-1 and SIVmus-2, co-circulate in the $C$. cephus cephus subspecies among animals living in the same geographic area [3]. SIVmus-1 and SIVmus2 are each other's closest relatives and form with SIVgsn from greater spot nosed monkeys (C. nictitans) and SIVmon from mona monkeys (C. mona) the SIVmus/mon/ gsn lineage. Importantly, SIVmus-2 is a recombinant lineage and consists of alternating sequences of SIVmus, SIVgsn and an unknown SIV in Gag and Pol proteomes. In the present study, the SIVmus-09GabOI81 strain is at the root of the SIVmus/mon/gsn lineage, strongly suggesting a new SIV lineage into this major lineage. Mustached monkeys appear to be the first NHP carrying three distinct SIVs. The basal position of SIVmus strain from Gabon among this lineage suggests a possible ancestrality of this virus in this clade or a more ancient infection within mustached monkeys from Gabon. However, it cannot be excluded that more detailed genetic analysis of the host will reveal a different subspecies. Similarity plot and bootscan analyses showed that this new variant is not recombinant in the studied fragment. Nonetheless, to date, recombination events have not been observed within the SIVs env gene and only fulllength genome analysis of this new SIVmus will clarify the genetic relationship with the other strains of the SIVmus/mon/gsn lineage, including the presence or not of a vpu gene. In addition, documenting and characterizing SIV infections within other C. cephus subspecies, but also within the same subspecies in other geographic areas, are required to further understand the genetic diversity of SIVs in mustached monkeys and their evolutionary history.

\section{Conclusion}

Our study identified high prevalence of retroviral infections and new STLV and SIV strains in a small sample size of NHP bushmeat in Gabon. Our data emphasize the need to perform larger studies on NHP retroviral 
infections, with a larger number of samples, a wider diversity of species and subspecies in African countries where NHPs are hunted for bushmeat. Similarly, as in other countries in Central Africa, bushmeat provides also an important source of protein in household diets in Gabon. Although NHPs are less hunted than other mammals, they represent, even so, about 12\% of hunters' preys [55]. Different studies showed that recent transmissions of simian retroviruses to human still occur [20,25,47]. Thus, it is important to identify and characterize retroviruses that circulate in African NHP species in order to estimate which retroviruses can potentially cross the species barrier and infect the human population. Previous studies on simian retroviruses in NHP bushmeat showed heterogeneous exposure in terms of prevalence and genetic diversity, depending on geographic areas studied and SIV's prevalence in predominantly hunted species, because SIV's prevalence can vary per species. Here we show that also among the same species, a high genetic diversity exist for SIVs and STLVs according to geographic origins.

\section{Methods}

\section{Study sites and animals}

Whole blood $(n=48)$ and lymph node tissues $(n=15)$ were obtained from 63 wild-caught monkey carcasses seized by agents of the provincial direction of the Gabon's Ministry of Water and Forests. Seven out of the 63 samples were collected from juvenile animals ( $<2$ years). Sampling was performed in eight provinces of Gabon from September 2009 to June 2010 (Figure 1). Species were initially determined by visual inspection according to the Kingdon Field Guide to African Mammals [56] and the taxonomy described by Colin Groves [40]. All NHP samples were obtained with the authorization of provincial inspections of Water and Forests. The Gabonese Ministry of National Education, Higher Education and Scientific Research and Innovation approved this study with the authorization $n^{\circ}$ AR0031/09/MENESRESI/ CENAREST/CG/CST/CSAR.

\section{Serological testing}

All whole blood samples were tested for the presence of STLV and/or SIV antibodies with commercially available confirmatory tests, INNOLIA HTLV-1/2 and INNOLIA HIV 1/2 (Innogenetics, Ghent, Belgium). These line immunoassays are able to discriminate between HTLV-1 and HTLV-2 and HIV-1 and HIV-2 cross-reactive antibodies, as previously described $[12,14]$. In addition, for the detection of SIV antibodies, an in-house strain-specific ELISA based assay using SIV lineage-specific V3-loop as antibody capture antigens was performed [57]. The SIV V3-loop peptides were chosen according to the NHP species encountered in Gabon: SIVmnd, SIVgsn/mus/mon, SIVrcm, SIVdeb, SIVlhoest/sun, SIVcol, SIVcpzGab1 and Gab2.

\section{DNA extraction, PCR and sequencing DNA extraction}

DNA was extracted from whole blood and/or tissues using Qiagen DNA extraction blood and tissues kits (Qiagen, Courtaboeuf, France). DNA integrity and monkey species were confirmed by amplification of glucose6-phosphate dehydrogenase gene (G6PDH) and mitochondrial 12sRNA gene respectively as previously described (Additional file 1: Figure 1) [14,58]. In addition, for the animal OI81, 12sRNA PCRs were done separately using extracted DNA from both whole blood and lymph node to confirm the monkey species.

\section{Molecular confirmation of STLV infection}

To confirm the presence of STLV infection in samples with HTLV cross-reactive antibodies, a diagnostic taxrex PCR (220 bp) allowing generic as well as typespecific detection of PTLVs was done. The generic PCR shows high sensitivity in detecting all PTLV groups, whereas the discriminatory PCRs have high specificities to discriminate between PTLV-1, PTLV-2 and PTLV-3 [59]. As previously reported, these different nested PCR protocols detect one to five infected cells with a DNA input from $10^{5}$ cells [59]. We also used this approach to directly detect the potential presence of STLV in samples for which only lymph node tissues were available $(\mathrm{n}=15)$.

For each STLV positive sample for which the tax-rex fragment was obtained, attempts to amplify an additional genomic fragment were done to confirm the phylogenetic clustering observed in the tax-rex region. A $450 \mathrm{bp}$ LTR fragment for STLV-1 was amplified with a semi-nested PCR using 8255not and LTRU5E primers for the first round and 8255not and 420LTR primers for the second round with the previously described cycling protocol $[12,59,60]$. Additionally, a 900 bp DNA fragment spanning the tax-pX-LTR region was sequenced for each STLV-3 positive sample, as previously reported [12].

\section{Molecular confirmation of SIV infection}

Attempts to amplify SIV sequences were done for all samples with HIV and/or SIV cross-reactive antibodies as well as for DNA extracted from the 15 samples for which only tissues were available. PCRs were done using consensus-degenerate pol primers, Polis4, Polis2 UNIPOL2, and PolOR with the following cycling PCR protocol for the first and second rounds: denaturation at $95^{\circ} \mathrm{C}$ for $2 \mathrm{~min}, 20$ cycles of denaturation at $95^{\circ} \mathrm{C}$ for $20 \mathrm{~s}$, hybridization at $45^{\circ} \mathrm{C}$ for $30 \mathrm{~s}$ and extension at $68^{\circ} \mathrm{C}$ for $1.30 \mathrm{~min}, 95^{\circ} \mathrm{C}$ for $2 \mathrm{~min}$ and 20 cycles of denaturation at $95^{\circ} \mathrm{C}$ for $20 \mathrm{~s}$, hybridization at $50^{\circ} \mathrm{C}$ for $30 \mathrm{~s}$ and extension at $68^{\circ} \mathrm{C}$ for $1.30 \mathrm{~min}$ with a final extension at $68^{\circ}$ C for $5 \mathrm{~min}$ [14]. 
Following the preliminary phylogenetic analyses, we decided to develop new molecular tools to amplify partial gag (470 bp), env (500 bp) as well as a longer pol fragment (1800 bp) to further analyze SIVrcm genetic diversity. We also developed new primers to amplify a $1900 \mathrm{bp}$ PCR product in the SIVmus env gene. All SIVrcm and SIVmus PCR products were obtained by using primers summarized in Additional file 2: Table S1 (see Additional file 2: Table S1).

PCR amplifications were performed using the Long Expand PCR kit (Roche Applied Science, Indianapolis, IN) according to the manufacturer's instructions. Each amplification reaction included a manual hot-start followed by 35 to 40 cycles. Annealing temperatures were set according to the primer melting temperatures. Extension times varied depending on the size of the expected fragment and were typically set at $1 \mathrm{~min} / \mathrm{kb}$.

For all STLV and SIV PCR experiments, reagents were prepared in a dedicated room. PCR products were purified on 1\% agarose-gel with a QBIOgene GENECLEAN $^{\circledR}$ Turbo kit (MP Biochemichals). Direct sequencing of both strands using the Big Dye terminator technology (ABI PRISM Big Dye Terminator Cycle Sequencing Ready Reaction kit with AmpliTaq FS DNA polymerase [PE Biosystems, Warrington, England]) was performed on an ABI 3130xl Genetic Analyser. Sequences were then assembled using the software package Lasergene (DNASTAR, Inc., MAD).

\section{Phylogenetic analyses}

Newly derived STLV and SIV nucleotide sequences were aligned with reference sequences from the GenBank by using MEGA4 with minor manual adjustments, if necessary [61]. Nucleotide sites that could not be unambiguously aligned were excluded from the analyses. Appropriate models of evolution were selected for each data set using Topali v2.5 software and maximum likelihood phylogenies were reconstructed using PhyML [62,63]. For STLV, analyses were performed using discrete gamma distribution to account for variable substitution rates among sites with four rate categories and the TN93 model. SIV analyses were done under the GTR $+\Gamma_{4}+\mathrm{I}$ model of evolution. Nucleotide frequencies, nucleotide changes rate and gamma distribution shape parameters were estimated from the data. The starting tree was obtained by using PhyML. One thousand bootstrap replications were performed to assess confidence in topology.

\section{Sequence similarity plots}

SIVmus partial env nucleotide sequence was aligned by using MEGA4 with minor manual adjustments [61]. Sites that could not be unambiguously aligned were excluded. The SIVmus partial env sequence was compared to representatives of known HIV/SIV lineages. In order to study whether the newly characterized SIVmus env sequence was recombinant with any of the other SIV lineages and more particularly with viruses from the SIVmus/mon/gsn lineage, similarity plot analysis was performed with the SIMPLOT package version 2.5 [64] using a sliding window of 160 nucleic acids (na) moved in steps of 10 na. For this purpose, a bootscan analysis was also realized.

\section{GenBank accession numbers}

The new sequences have been deposited in EMBL under the following accession numbers:

STLV-1 partial tax sequences (HE589471-HE589483), STLV-1 partial LTR sequences (HE589484-HE589493), STLV-3 partial tax sequences (HE591390-HE591393), STLV-3 partial $p X$-LTR sequences (HE591394-HE591396), SIV partial pol sequences (HE591397-HE591403), SIVrcm partial gag sequences (HE591404-HE591408), SIVrcm partial env sequences (HE591409-HE591413), SIVmus partial env sequence (HE591414).

\section{Additional files}

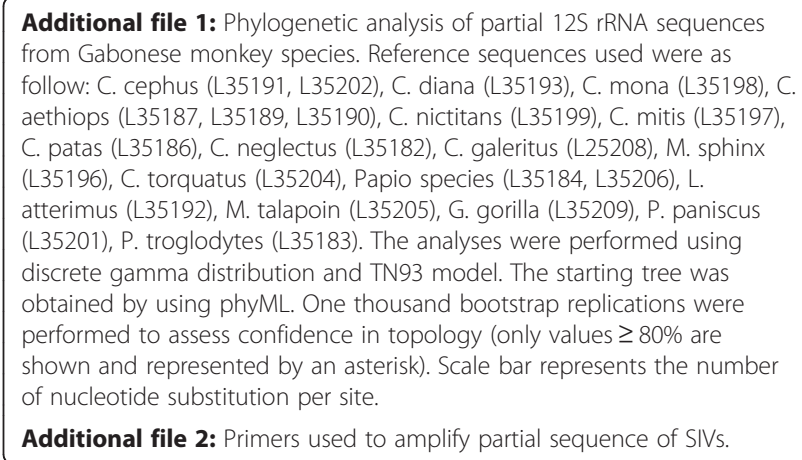

Competing interests

The authors declare that they have no competing interests.

\section{Acknowledgments}

This work was supported in part by the Centre International de Recherches Médicales de Franceville (CIRMF), the Institut de Recherche pour le Développement (IRD) and by grants from the National Institute of Health (RO1 Al 50529) and the Agence Nationale de Recherches sur le SIDA (ANRS 12182). We thank the Gabon's Ministry of Water and Forests. We thank Philippe Engandja for his collaboration and participation in this study. We grateful thank Edward D. Greenwood and Michael Nagel for their thorough corrections.

\section{Author details}

1UMI 233, «Trans VIH Ml», Recherches Translationnelles sur le VIH et les Maladies Infectieuses Institut de Recherche pour le Développement (IRD), University of Montpellier 1, Montpellier, France. ${ }^{2}$ Laboratoire de Rétrovirologie, Centre International de Recherches Médicales de Franceville, Franceville, Gabon. ${ }^{3}$ UMR MIVEGEC, (IRD224-CNRS5290, University of Montpellier 1 \& 2), Montpellier, France. ${ }^{4}$ Centre International de Recherches Médicales de Franceville, BP 769, Franceville, Gabon, Africa. 


\section{Authors' contributions}

Conceived and designed the experiments: FL, MP, FR, EL. Performed the experiments: FL, VB, FM, CB. Analyzed the data: FL, MP, FR, VB. Contributed reagents/materials/analysis tools: FL, MP, EL, XP, BMO. Wrote the paper: FL, MP, FR, EL. Study conducted in the field: EL, XP, BMO. All authors read and approved the final manuscript.

\section{Received: 24 October 2011 Accepted: 30 March 2012}

Published: 30 March 2012

\section{References}

1. Aghokeng AF, Peeters M: Simian immunodeficiency viruses (SIVs) in Africa. J Neurovirol 2005, 11(Suppl 1):27-32.

2. Aghokeng AF, Ayouba A, Mpoudi-Ngole E, Loul S, Liegeois F, Delaporte E, Peeters M: Extensive survey on the prevalence and genetic diversity of SIVs in primate bushmeat provides insights into risks for potential new cross-species transmissions. Infect Genet Evol 2010, 10(3):386-396.

3. Aghokeng AF, Bailes E, Loul S, Courgnaud V, Mpoudi-Ngolle E, Sharp PM, Delaporte E, Peeters M: Full-length sequence analysis of SIVmus in wild populations of mustached monkeys (Cercopithecus cephus) from Cameroon provides evidence for two co-circulating SIVmus lineages. Virology 2007, 360(2):407-418

4. Ahuka-Mundeke S, Liegeois F, Ayouba A, Foupouopouognini Y, Nerriennet E, Delaporte E, Peeters M: Full-length genome sequence of a Simian Immunodeficiency Virus infecting a captive Agile Mangabey (Cercocebus agilis) is closely related to SIVrcm infecting wild red-capped mangabeys (Cercocebus torquatus) in Cameroon. J Gen Virol 2010, 91(Pt 12):2959-2964.

5. Ahuka-Mundeke SAA, Mbala-Kingebeni $P$, Liegeois F, Esteban A, LunguyaMetila O, Demba D, Bilulu G, Mbenzo-Abokome V, Inogwabini B-I, Muyembe-Tamfum J-J, Delaporte E, Peeters M: A novel multiplexed HIV/SIV antibody detection assay identified new simian immunodeficiency viruses in primate bushmeat in the Democraphic Republic of Congo. Emerg Infect Dis 2011, 17(12):2277-2286.

6. Dazza MC, Ekwalanga M, Nende M, Shamamba KB, Bitshi P, Paraskevis D, Saragosti S: Characterization of a novel vpu-harboring simian immunodeficiency virus from a Dent's Mona monkey (Cercopithecus mona denti) J Virol 2005, 79(13):8560-8571.

7. Goldberg TL, Sintasath DM, Chapman CA, Cameron KM, Karesh WB, Tang S, Wolfe ND, Rwego IB, Ting N, Switzer WM: Coinfection of Ugandan red colobus (Procolobus [Piliocolobus] rufomitratus tephrosceles) with novel, divergent delta-, lenti-, and spumaretroviruses. J Virol 2009, 83 (21):11318-11329.

8. Leendertz FH, Junglen S, Boesch C, Formenty P, Couacy-Hymann E, Courgnaud V, Pauli G, Ellerbrok H: High variety of different simian T-cell leukemia virus type 1 strains in chimpanzees (Pan troglodytes verus) of the Tai National Park, Cote d'Ivoire. J Virol 2004, 78(8):4352-4356

9. Leendertz SA, Junglen S, Hedemann C, Goffe A, Calvignac S, Boesch C, Leendertz FH: High prevalence, coinfection rate, and genetic diversity of retroviruses in wild red colobus monkeys (Piliocolobus badius badius) in Tai National Park, Cote d'Ivoire. J Virol 2010, 84(15):7427-7436.

10. Liegeois F, Butel C, Mouinga-Ondeme A, Verrier D, Motsch P, Gonzalez JP, Peeters M, Rouet F, Onanga R: Full-Length Genome Sequence of a Simian Immunodeficiency Virus from a Wild-Captured Sun-Tailed Monkey in Gabon Provides Evidence for a Species-Specific Monophyletic SIVsun Lineage. AIDS Res Hum Retroviruses 2011, 27(11):1237-1241.

11. Liegeois F, Lafay B, Formenty P, Locatelli S, Courgnaud V, Delaporte E, Peeters M: Full-length genome characterization of a novel simian immunodeficiency virus lineage (SIVolc) from olive Colobus (Procolobus verus) and new SIVwrcPbb strains from Western Red Colobus (Piliocolobus badius badius) from the Tai Forest in Ivory Coast. J Virol 2009, 83(1):428-439.

12. Liegeois F, Lafay B, Switzer WM, Locatelli S, Mpoudi-Ngole E, Loul S, Heneine W, Delaporte E, Peeters M: Identification and molecular characterization of new STLV-1 and STLV-3 strains in wild-caught nonhuman primates in Cameroon. Virology 2008, 371(2):405-417.

13. Ahuka-Mundeke $S$, Mbala-Kingebeni $P$, Liegeois F, Ayouba A, Lunguya-Metila O, Demba D, Bilulu G, Mbenzo-Abokome V, Inogwabini Bl, MuyembeTamfum JJ, Delaporte E, Peeters M: Identification and Molecular Characterization of New Simian T Cell Lymphotropic Viruses in
Nonhuman Primates Bushmeat from the Democratic Republic of Congo. AIDS Res Hum Retroviruses, September 2011, (Epub ahead of print).

14. Peeters M, Courgnaud V, Abela B, Auzel P, Pourrut X, Bibollet-Ruche F, Loul S, Liegeois F, Butel C, Koulagna D, Mpoudi-Ngole E, Shaw GM, Hahn BH, Delaporte E: Risk to human health from a plethora of simian immunodeficiency viruses in primate bushmeat. Emerg Infect Dis 2002, 8 (5):451-457.

15. Nerrienet $E$, Amouretti $X$, Muller-Trutwin MC, Poaty-Mavoungou V, Bedjebaga I, Nguyen HT, Dubreuil G, Corbet S, Wickings EJ, Barre-Sinoussi F Georges AJ, Georges-Courbot MC: Phylogenetic analysis of SIV and STLV type I in mandrills (Mandrillus sphinx): indications that intracolony transmissions are predominantly the result of male-to-male aggressive contacts. AIDS Res Hum Retroviruses 1998, 14(9):785-796.

16. Locatelli S, Lafay B, Liegeois F, Ting N, Delaporte E, Peeters M: Full molecular characterization of a simian immunodeficiency virus, SIVwrcpbt from Temminck's red colobus (Piliocolobus badius temminckii) from Abuko Nature Reserve, The Gambia. Virology 2008, 376(1):90-100.

17. Hahn BH, Shaw GM, De Cock KM, Sharp PM: AIDS as a zoonosis: scientific and public health implications. Science 2000, 287(5453):607-614.

18. Keele BF, Van Heuverswyn F, Li Y, Bailes E, Takehisa J, Santiago ML, BibolletRuche F, Chen Y, Wain LV, Liegeois F, Loul S, Ngole EM, Bienvenue Y, Delaporte E, Brookfield JF, Sharp PM, Shaw GM, Peeters M, Hahn BH: Chimpanzee reservoirs of pandemic and nonpandemic HIV-1. Science 2006, 313(5786):523-526.

19. Van Heuverswyn F, Li Y, Neel C, Bailes E, Keele BF, Liu W, Loul S, Butel C, Liegeois F, Bienvenue Y, Ngolle EM, Sharp PM, Shaw GM, Delaporte E, Hahn $\mathrm{BH}$, Peeters M: Human immunodeficiency viruses: SIV infection in wild gorillas. Nature 2006, 444(7116):164.

20. Plantier JC, Leoz M, Dickerson JE, De Oliveira F, Cordonnier F, Lemee V, Damond F, Robertson DL, Simon F: A new human immunodeficiency virus derived from gorillas. Nat Med 2009, 15(8):871-872.

21. Santiago ML, Range F, Keele BF, Li Y, Bailes E, Bibollet-Ruche F, Fruteau C, Noe R, Peeters M, Brookfield JF, Shaw GM, Sharp PM, Hahn BH: Simian immunodeficiency virus infection in free-ranging sooty mangabeys (Cercocebus atys atys) from the Tai Forest, Cote d'Ivoire: implications for the origin of epidemic human immunodeficiency virus type 2. J Virol 2005, 79(19):12515-12527.

22. Calattini S, Betsem E, Bassot S, Chevalier SA, Tortevoye P, Njouom R, Mahieux R, Froment A, Gessain A: Multiple retroviral infection by HTLV type 1, 2, 3 and simian foamy virus in a family of Pygmies from Cameroon. Virology 2011, 410(1):48-55.

23. Gessain A: Human retrovirus HTLV-1: descriptive and molecular epidemiology, origin, evolution, diagnosis and associated diseases. Bull Soc Pathol Exot 2011, 104(3):167-180.

24. Wolfe ND, Heneine W, Carr JK, Garcia AD, Shanmugam V, Tamoufe U, Torimiro JN, Prosser AT, Lebreton M, Mpoudi-Ngole E, McCutchan FE, Birx $D L$, Folks TM, Burke DS, Switzer WM: Emergence of unique primate Tlymphotropic viruses among central African bushmeat hunters. Proc Natl Acad Sci U S A 2005, 102(22):7994-7999.

25. Zheng H, Wolfe ND, Sintasath DM, Tamoufe U, Lebreton M, Djoko CF, Diffo Jle D, Pike BL, Heneine W, Switzer WM: Emergence of a novel and highly divergent HTLV-3 in a primate hunter in Cameroon. Virology 2010, 401(2):137-145.

26. Ahuka-Mundeke SLF, Lunguya O, Mbenzo V, Mbende M, Inogwabini B-I, Ayouba A, Muyembe J-J, Delaporte E, Peeters M: Evidence of STLV 2 and STLV 3 infections in wild living bonobos (P. paniscus) from the Democratic Republic of Congo. Retrovirology 2011, 8(Suppl 1):93.

27. Meertens L, Gessain A: Divergent simian T-cell lymphotropic virus type 3 (STLV-3) in wild-caught Papio hamadryas papio from Senegal: widespread distribution of STLV-3 in Africa. J Virol 2003, 77 (1):782-789.

28. Salemi M, Van Dooren S, Audenaert E, Delaporte E, Goubau P, Desmyter J, Vandamme AM: Two new human T-lymphotropic virus type I phylogenetic subtypes in seroindeterminates, a Mbuti pygmy and a Gabonese, have closest relatives among African STLV-I strains. Virology 1998, 246(2):277-287.

29. Liu HF, Goubau P, Van Brussel M, Van Laethem K, Chen YC, Desmyter J, Vandamme AM: The three human T-lymphotropic virus type I subtypes arose from three geographically distinct simian reservoirs. J Gen Virol 1996, 77(Pt 2):359-368

30. Koralnik IJ, Boeri E, Saxinger WC, Monico AL, Fullen J, Gessain A, Guo HG, Gallo RC, Markham P, Kalyanaraman V, et al: Phylogenetic associations of 
human and simian T-cell leukemia/lymphotropic virus type I strains: evidence for interspecies transmission. J Virol 1994, 68(4):2693-2707.

31. Vandamme AM, Salemi M, Desmyter J: The simian origins of the pathogenic human T-cell lymphotropic virus type 1. Trends Microbiol 1998 6(12):477-483

32. Beer BE, Bailes E, Goeken R, Dapolito G, Coulibaly C, Norley SG, Kurth R, Gautier JP, Gautier-Hion A, Vallet D, Sharp PM, Hirsch VM: Simian immunodeficiency virus (SIV) from sun-tailed monkeys (Cercopithecus solatus): evidence for host-dependent evolution of SIV within the C. Ihoesti superspecies. J Virol 1999, 73(9):7734-7744.

33. Bibollet-Ruche F, Bailes E, Gao F, Pourrut X, Barlow KL, Clewley JP, Mwenda JM, Langat DK, Chege GK, McClure HM, Mpoudi-Ngole E, Delaporte E, Peeters M, Shaw GM, Sharp PM, Hahn BH: New simian immunodeficiency virus infecting De Brazza's monkeys (Cercopithecus neglectus): evidence for a cercopithecus monkey virus clade. I Virol 2004, 78(14):7748-7762.

34. Allan JS, Short M, Taylor ME, Su S, Hirsch VM, Johnson PR, Shaw GM, Hahn $\mathrm{BH}$ : Species-specific diversity among simian immunodeficiency viruses from African green monkeys. J Virol 1991, 65(6):2816-2828.

35. Souquiere S, Bibollet-Ruche F, Robertson DL, Makuwa M, Apetrei C, Onanga R, Kornfeld C, Plantier JC, Gao F, Abernethy K, White LJ, Karesh W, Telfer P, Wickings EJ, Mauclere P, Marx PA, Barre-Sinoussi F, Hahn BH, Muller-Trutwin MC, Simon F: Wild Mandrillus sphinx are carriers of two types of lentivirus. J Virol 2001, 75(15):7086-7096.

36. Bibollet-Ruche F, Galat-Luong A, Cuny G, Sarni-Manchado P, Galat G, Durand JP, Pourrut $X$, Veas F: Simian immunodeficiency virus infection in a patas monkey (Erythrocebus patas): evidence for cross-species transmission from African green monkeys (Cercopithecus aethiops sabaeus) in the wild. J Gen Virol 1996, 77(Pt 4):773-781.

37. Jin MJ, Rogers J, Phillips-Conroy JE, Allan JS, Desrosiers RC, Shaw GM, Sharp PM, Hahn BH: Infection of a yellow baboon with simian immunodeficiency virus from African green monkeys: evidence for cross-species transmission in the wild. J Virol 1994, 68(12):8454-8460.

38. van Rensburg EJ, Engelbrecht S, Mwenda J, Laten JD, Robson BA, Stander T, Chege GK: Simian immunodeficiency viruses (SIVs) from eastern and southern Africa: detection of a SIVagm variant from a chacma baboon. $J$ Gen Virol 1998, 79(Pt 7):1809-1814

39. Bailes E, Gao F, Bibollet-Ruche F, Courgnaud V, Peeters M, Marx PA, Hahn BH, Sharp PM: Hybrid origin of SIV in chimpanzees. Science 2003, 300 (5626):1713.

40. Groves C: Primate taxonomy. Smithsonian series in comparative evolutionary biology, 2001. Smithsonian Institution Press

41. Courgnaud V, Van Dooren S, Liegeois F, Pourrut X, Abela B, Loul S, MpoudiNgole E, Vandamme A, Delaporte E, Peeters M: Simian T-cell leukemia virus (STLV) infection in wild primate populations in Cameroon: evidence for dual STLV type 1 and type 3 infection in agile mangabeys (Cercocebus agilis) J Virol 2004, 78(9):4700-4709.

42. Makuwa M, Souquiere S, Clifford SL, Telfer PT, Salle B, Bourry O, Onanga R, Mouinga-Ondeme A, Wickings EJ, Abernethy KA, Rouquet P, Simon F, Roques P: Two distinct STLV-1 subtypes infecting Mandrillus sphinx follow the geographic distribution of their hosts. AIDS Res Hum Retroviruses 2004, 20(10):1137-1143.

43. Makuwa $M$, Souquiere $S$, Telfer $P$, Mouinga-Ondeme $A$, Bourry $O$, Roques $P$ : A New STLV-1 in a household pet Cercopithecus nictitans from Gabon. AIDS Res Hum Retroviruses 2004, 20(6):679-683.

44. Calattini S, Betsem E, Bassot S, Chevalier SA, Mahieux R, Froment A, Gessain A: New strain of human T lymphotropic virus (HTLV) type 3 in a Pygmy from Cameroon with peculiar HTLV serologic results. J Infect Dis 2009, 199(4):561-564.

45. Calattini S, Chevalier SA, Duprez R, Bassot S, Froment A, Mahieux R, Gessain A: Discovery of a new human T-cell lymphotropic virus (HTLV-3) in Central Africa. Retrovirology 2005, 2(1):30.

46. Meertens L, Mahieux R, Mauclere P, Lewis J, Gessain A: Complete sequence of a novel highly divergent simian T-cell lymphotropic virus from wild-caught red-capped mangabeys (Cercocebus torquatus) from Cameroon: a new primate T-lymphotropic virus type 3 subtype. J Virol 2002, 76(1):259-268.

47. Mouinga-Ondeme A, Betsem E, Caron M, Makuwa M, Salle B, Renault N, Saib A, Telfer P, Marx P, Gessain A, Kazanji M: Two distinct variants of simian foamy virus in naturally infected mandrills (Mandrillus sphinx) and cross-species transmission to human. Retrovirology 2010, 7:105.
48. Worobey M, Telfer $P$, Souquiere $S$, Hunter M, Coleman CA, Metzger MJ, Reed P, Makuwa M, Hearn G, Honarvar S, Roques P, Apetrei C, Kazanji M, Marx PA: Island biogeography reveals the deep history of SIV. Science 2010, 329 (5998):1487.

49. Aghokeng AF, Liu W, Bibollet-Ruche F, Loul S, Mpoudi-Ngole E, Laurent C, Mwenda JM, Langat DK, Chege GK, McClure HM, Delaporte E, Shaw GM, Hahn BH, Peeters M: Widely varying SIV prevalence rates in naturally infected primate species from Cameroon. Virology 2006, 345(1):174-189.

50. Sintasath DM, Wolfe ND, Lebreton M, Jia H, Garcia AD, Le Doux-Diffo J, Tamoufe U, Carr JK, Folks TM, Mpoudi-Ngole E, Burke DS, Heneine W, Switzer WM: Simian T-lymphotropic virus diversity among nonhuman primates, Cameroon. Emerg Infect Dis 2009, 15(2):175-184.

51. Apetrei C, Metzger MJ, Richardson D, Ling B, Telfer PT, Reed P, Robertson $\mathrm{DL}$, Marx PA: Detection and partial characterization of simian immunodeficiency virus SIVsm strains from bush meat samples from rural Sierra Leone. J Virol 2005, 79(4):2631-2636.

52. Blom A, Alers MPT, Feistner ATC, Barnes RFW, Barnes KL: Primates in Gabon-Current status and distribution. Oryx 1992, 26(04):223-234

53. Locatelli $S$, Liegeois $F$, Lafay $B$, Roeder AD, Bruford MW, Formenty $P$, Noe $R$, Delaporte $E$, Peeters M: Prevalence and genetic diversity of simian immunodeficiency virus infection in wild-living red colobus monkeys (Piliocolobus badius badius) from the Tai forest, Cote d'Ivoire SIVwrc in wild-living western red colobus monkeys. Infect Genet Evol 2008, 8(1):1-14.

54. Gautier-Hion A, Colyn M, Gautier J-P: Histoire naturelle des primates d'afrique centrale. Ecofac 1999.

55. Fa E, John RFS, Diana Bell J: Hunting vulnerability, ecological characteristics and harvest rates of bushmeat species in afrotropical forests. Biol Conserv 2005, 121:167-176.

56. Kingdon J: The Kingdon Field Guide to African Mammals. Academic Press; 1997

57. Simon F, Souquiere S, Damond F, Kfutwah A, Makuwa M, Leroy E, Rouquet P, Berthier JL, Rigoulet J, Lecu A, Telfer PT, Pandrea I, Plantier JC, Barre-Sinoussi F, Roques P, Muller-Trutwin MC, Apetrei C: Synthetic peptide strategy for the detection of and discrimination among highly divergent primate lentiviruses. AIDS Res Hum Retroviruses 2001, 17(10):937-952.

58. van der Kuyl AC, Dekker JT, Goudsmit J: Primate genus Miopithecus: evidence for the existence of species and subspecies of dwarf guenons based on cellular and endogenous viral sequences. Mol Phylogenet Evol 2000, 14(3):403-413.

59. Vandamme AM, Van Laethem K, Liu HF, Van Brussel M, Delaporte E, de Castro Costa CM, Fleischer C, Taylor G, Bertazzoni U, Desmyter J, Goubau P. Use of a generic polymerase chain reaction assay detecting human Tlymphotropic virus (HTLV) types I, II and divergent simian strains in the evaluation of individuals with indeterminate HTLV serology. J Med Virol 1997, 52(1):1-7.

60. Mahieux R, Ibrahim F, Mauclere P, Herve V, Michel P, Tekaia F, Chappey C, Garin B, Van Der Ryst E, Guillemain B, Ledru E, Delaporte E, de The G, Gessain A: Molecular epidemiology of 58 new African human T-cell leukemia virus type 1 (HTLV-1) strains: identification of a new and distinct HTLV-1 molecular subtype in Central Africa and in Pygmies. J Virol 1997, 71(2):1317-1333.

61. Tamura K, Dudley J, Nei M, Kumar S: MEGA4: Molecular Evolutionary Genetics Analysis (MEGA) software version 40. Mol Biol Evol 2007, 24 (8):1596-1599.

62. Milne I, Lindner D, Bayer M, Husmeier D, McGuire G, Marshall DF, Wright F: TOPALi v2: a rich graphical interface for evolutionary analyses of multiple alignments on HPC clusters and multi-core desktops. Bioinformatics 2009, 25(1):126-127.

63. Guindon S, Dufayard JF, Lefort V, Anisimova M, Hordijk W, Gascuel O: New algorithms and methods to estimate maximum-likelihood phylogenies: assessing the performance of PhyML 30. Syst Biol 2010, 59(3):307-321.

64. Ray S: SImPLot version 2.5 software. Documentation, 1999

doi:10.1186/1742-4690-9-28

Cite this article as: Liégeois et al:: New STLV-3 strains and a divergent SIVmus strain identified in non-human primate bushmeat in Gabon. Retrovirology 2012 9:28. 